\title{
Correspondence
}

We welcome letters to the Editor concerning articles which have recently been published. Such letters will be subject to the usual stages of selection and editing; where appropriate the authors of the original article will be offered the opportunity to reply.

Letters should normally be under 300 words in length, double-spaced throughout, signed by all authors and fully referenced. The edited version will be returned for approval before publication.

\section{Ankle fractures in diabetics}

Sir,

I read with interest the report in the July 1998 issue entitled 'Ankle fractures in diabetics' 1 and wish to make the following observations.

In my experience, the major problem has been early weightbearing on an ankle which has been internally fixed. The neuropathy allows painless weight-bearing without protective sensation. This results in the displacement of the fracture and subsequent wound problems.

In my practice, all diabetic patients wear a long-leg cast for a period of six to eight weeks following internal fixation of fractures of the ankle and foot, and reconstructive bony operations. The knee is bent to approximately $70^{\circ}$ to inhibit weight-bearing. This can be a social strain on the patient usually relegating them to a wheelchair. I have found, however, that this prevents wound problems and loss of fixation. For bimalleolar patterns, I commonly use staple fixation of the syndesmosis (Cedell), which provides an additional buttress against lateral rotatory displacement of the fibula.

J. B. CARR, MD

Medical College of Virginia

Richmond, Virginia, USA.

1. McCormack RG, Leith JM. Ankle fractures in diabetes: complications of surgical management. J Bone Joint Surg [Br] 1998;80-B: 689-92.

\section{Author's reply:}

Sir,

We appreciate Dr Carr's comments. The patients in our review were instructed to remain non-weight-bearing until the fracture had healed, but we did not place them in a long-leg cast to enforce this. This would have resulted in functional disability for these often elderly patients which might have precluded discharge from hospital.
It is difficult to comment on his specific surgical technique. In our review, patients were treated using AO principles, but it is possible that special techniques are necessary in subgroups of patients. The main point of our article was to recognise that foot and ankle injuries in diabetics have different risks and prognosis. Some form of prospective trial would be needed to define better the optimal form of treatment.

\section{R. G. McCORMACK, MD, FRCS C \\ University of British Columbia Westminster, British Columbia Canada.}

\section{Severe progressive deformities after limb lengthening in type-II fibular hemimelia}

\section{Sir,}

I write with reference to the paper in the September 1998 issue by Cheng et $\mathrm{al}^{1}$ entitled 'Severe progressive deformities after limb lengthening in type-II fibular hemimelia'. The deformity which they describe is a result of continued growth in an abnormal epiphysis, combined with an unstable ankle. In these type-II cases, serious consideration should be given as to whether the foot is worth preserving. If it is, then excision of the distal tibial epiphysis and ankle arthrodesis give a functional limb and avoid deformity. When this is planned beforehand, it can be carried out at the same time as the application of the Ilizarov frame, and the amount of lengthening is suitably adjusted.

R. J. MONTGOMERY, FRCS

Middlesbrough General Hospital

Middlesbrough, UK.

1. Cheng JCY, Cheung KW, Ng BKW. Severe progressive deformities after limb lengthening in type-II fibular hemimelia. J Bone Joint Surg [Br] 1998;80-B:772-6.

\section{Author's reply:}

Sir,

We thank Mr Montgomery for his comment. As we have indicated in our discussion it is necessary to reappraise the indications for lengthening in severe type-II fibular hemimelia. The results from either Syme's, Boyd's or modified Boyd's amputation have been very good in medium- and long-term follow-up studies in centres with good prosthetic and orthotic support.

His suggestion of excision of the distal tibial epiphysis and ankle arthrodesis at the same time as the Ilizarov lengthening is interesting. Many of these type-II patients have an abnormal bony alignment and anatomy of the foot and the talus is often absent. It may not be easy to carry out adequate ankle arthrodesis and the subsequent growth of the foot after the arthrodesis is uncertain. We prefer either to arthrodese at a later stage as a secondary or tertiary procedure after lengthening has been completed, nearer to skeletal maturity, or to proceed to a modified Boyd's amputation without lengthening at the initial stage.

J. C. Y. CHENG, FRCS Ed(Orth)

Prince of Wales Hospital

Hong Kong.
C01999 British Editorial Society of Bone and Joint Surgery

0301-620X/99/19629 $\$ 2.00$

J Bone Joint Surg [Br] 1999;81-B:178-82. 


\section{Ultrasonography in developmental hip dysplasia}

Sir

I read with interest the paper by Bar-On et al $^{1}$ in the March 1998 issue entitled 'Ultrasonography of the hip in developmental hip dysplasia'. In order to carry out reproducible quantification of the acetabular roof, it is necessary to establish a standard plane of measurement which, according to Graf and Wilson, ${ }^{2}$ can only be the middle or true coronal plane, since the dorsal part of the bony roof of the acetabulum is in general very well developed. This peculiarity implies that, if a cut is taken through the acetabulum running through the dorsal part of the edge of the socket, a relatively good bony roof is always shown. ${ }^{2}$ I think that there is such an error in Figure 4a which resulted in the dislocated hip being classified as type I. The lack of an osteochondral junction in Figure 1 indicates that the sonogram is not ideal, probably due to the tilt of the transducer. Such errors in applying Graf's technique and in the evaluation of the sonograms may have lead to moderate or fair intra- and interobserver reliability as concluded by the authors' article.

A. ÖZÇELIK, MD

Osmangazi University Hospital

Eskisehir, Turkey.

1. Bar-On E, Meyer S, Harari G , Porat S. Ultrasonography of the hip in developmental hip dysplasia. J Bone Joint Surg [Br] 1998;80-B: $321-4$.

2. Graf R, Wilson B. Sonography of the infant hip and its therapeutic implications. London, etc: Chapman \& Hall, 1995;53-65.

\section{Author's reply:}

Sir,

Dr Özçelik outlines potential sources of inaccuracy in ultrasonography of the infant hip, some of which he identified in the Figures presented in our paper.

Although I fully agree with all his comments regarding the potential causes of reduced accuracy, we did not attempt to analyse the reasons for the inaccuracies, but only to examine the variability in performance and interpretation of sonograms. These were considered acceptable by the interpreters for measuring the end result, i.e., the Graf classification and need for treatment.

E. BAR-ON, MD

Schneider Children's Medical Centre

Petach-Tikva, Israel.

\section{Wear of polyethylene in artificial hip joints}

Sir,

The recent Editorial ${ }^{1}$ in the March 1998 issue entitled 'Wear of polyethylene in artificial hip joints' seemed one-sided in that it emphasised the engineering aspects to the exclusion of the biological. True, the author mentions phagocytosis, particularly of submicron-sized particles, but its implications are ignored.

Abrasion in vivo differs from that in other situations in one particular respect; the enhanced reactivity of the surfaces of the particles (and also of the parent polymer) promotes their reactions with abutting fluid and tissue.

It is well known that, whatever the substance, be it metal or polymer, the smaller the particle, the greater is the reactivity of the surface layer. Therefore submicron particles of necessity lose the 'inertness' for which the parent polymer derives its utility.

It also follows that the volume of abraded polyethylene is not particularly meaningful when the size distribution of the particles or the degree of enhancement of reactivity is not known or cannot be determined.
The clinical aspect of this reactivity, which may be manifest in osteolysis as well as phagocytosis, is obvious. Not so obvious is its influence on experiments. Often particles are used that have been manufactured in ways that are not well described in the reports and the size distribution is similarly deficient.

\section{J. COHEN, MD}

Franciscan Children's Hospital Boston, USA.

1. Fisher J. Wear of polyethylene in artificial hip joints: superolateral wear of the acetabulum. J Bone Joint Surg [Br] 1998;80-B:190-1.

\section{Author's reply:}

Sir,

I welcome Dr Cohen's response to my Editorial which opens up the issue of the biological reactivity of wear particles.

$\mathrm{He}$ is correct in inferring that biological response is not controlled directly by wear volume, but more specifically by the number, size and morphology of the wear particles and their chemical and biochemical reactivity. The effect of the size of polyethylene particles and their number or concentration on the biological reactivity has recently been demonstrated, with particles in the range of 0.2 to $7 \mu \mathrm{m}$ being the most active. ${ }^{1,2}$ The implications of these findings are important. It is now recognised that in order to study the reactivity of wear particles it is important to generate real debris with the correct morphology.

Recent studies have also shown that as the composition of polyethylene is altered the size and number of wear particles change. ${ }^{3}$ This indicates that as we study alternative or modified polyethylenes, we should not just consider their performance in terms of wear volume, but also need to characterise the wear particles produced and to study the biological reactivity. If we can do this we will be in a much better position to predict long-term clinical performance and osteolytic potential from preclinical studies.

J. FISHER, BSc, PhD, DEng, CEng, FIMechE

University of Leeds

Leeds, UK.

1. Green TR, Fisher J, Ingham E. Polyethylene particles of a critical size are necessary for the induction of TNF alpha by macrophages in vitro. Trans Orthop Res Soc 1998;44:124.

2. Green TR, Matthews JB, Fisher J, Ingham E. Cytosine production by macrophages in response to clinically relevant UHMWPE debris of different sizes. Trans Orthop Res Soc 1998;44:374.

3. Besong AA, Tipper JL, Ingham E, Stone MH, et al. Quantitative comparison of wear debris from UHMWPE that has and has not been sterilised by gamma irradiation. J Bone Joint Surg [Br] 1998;80-B: $340-4$.

\section{Prognosis in Perthes' disease}

Sir,

In the article in the March 1998 issue entitled 'Prognosis in Perthes' disease: a comparison of radiological predictors', Ismail and Macnicol $^{1}$ have shown that the Herring lateral pillar grading and sphericity of the femoral head determined by arthrography, together with the age of onset of the disease, are the most accurate prognostic indicators.

The paper shows means of identifying the likely outcome of the disease but it does not offer much help in improving the outcome. 
Establishment of the prognosis and monitoring of the disease for therapeutic decision-making may be confounded. When Catterall $^{2}$ introduced his grouping and concept of 'head at risk' he was probably aiming more at treatment than at the establishment of the prognosis, although the need for operative treatment may be related to prognosis. His classification can be applied to MRI and can be used early. Herring's lateral pillar grouping, however, does not help decision-making since it can only be established late in the disease in the fragmentation stage.

It is well accepted that the crucial point in those hips that do badly is loss of containment, i.e., loss of acetabular coverage (epiphyseal protrusion) with possible superolateral subluxation (extrusion of the femoral head). What we need is monitoring of the onset of loss of containment for timely institution of treatment such as strict non-weight-bearing, as outlined in the paper, or well-known operative procedures aiming at improvement of containment.

I feel that the most important signs of early loss of containment are enlargement of the cartilaginous head ${ }^{3,4}$ and a labrum lift. The latter can be seen on MRI. ${ }^{5,6}$ It is less clear on arthrography. The labrum lift in loss of containment has been well known from the postmortem studies by Catterall et $\mathrm{al}^{7}$ and has more recently been addressed by de Sanctis.

I believe that in Perthes' disease monitoring for the onset of loss of containment is more important than establishing prognostic indicators. MRI has become an important non-invasive diagnostic tool for monitoring the disease and for decision-making at any stage. In most cases we are able to operate before there is a severe deformity such as indentation of the epiphysis by the acetabular rim and the presence of hinge abduction. It is therefore not necessary to determine the best position for containment.

In addition, MRI allows the recognition of physeal involvement which has been found to be a strong predictor of prognosis. ${ }^{9-11}$

\section{MEISS, MD}

Orthopädische Universitätsklinik

Hamburg, Germany.

1. Ismail AM, Macnicol MF. Prognosis in Perthes' disease: a comparison of radiological predictors. J Bone Joint Surg [Br] 1998;80-B: $310-4$.

2. Catterall A. The natural history of Perthes' disease. J Bone Joint Surg [Br] 1971;53-B:37-53.

3. Lange F, Meiss L, Korn U. Cartilaginous coxa magna in the initial stage of LCP disease: MR findings of pathogenetic significance. 15th Meeting of the European Pediatric Orthopaedic Society, Prague, 1996.

4. Meiss L, Lund C. The maximum oblique diameter (MOD): a new parameter for decision-making in Legg-Calvé-Perthes' disease. 25th International Pediatric Orthopedic Seminar, Chicago, 1997.

5. Meiss L, Dahmen GP, Schaefer B. Zur Kernspintomographie beim Morbus Perthes. 9th Annual Meeting of the Vereinigung für Kinderorthopädie, Graz, 1995.

6. Meiss L, Lange F. Wesentliche MR-Parameter zur Verlaufsbeurteilung des Morbus Perthes. 47th Annual Meeting of the Norddeutsche Orthopädenvereinigung, Leipzig, 1998.

7. Catterall A, Pringle J, Byders PD, Fulford GE, Kemp HBS. Perthes' disease: is the epiphyseal infarction complete? J Bone Joint Surg [Br] 1982;64-B:276-81.

8. de Sanctis N. New assessment of diagnosis and prognosis of Perthes' disease. 11th Annual Meeting of the Vereinigung für Kinderorthopädie, Zürich, 1997.

9. Jaramillo D, Kasser JR, Villegas-Medina OL, Gaary E, Zurakowski D. Cartilaginous abnormalities and growth disturbances in Legg-Calvé-Perthes disease: evaluation with MR imaging. Radiology 1995;197:767-73

10. Nunziata Rega A, de Sanctis N. The behaviour of the growth plate in Perthes' disease: MRI study. 17th Meeting of the European Pediatric Orthopaedic Society, Madrid, 1998.

11. Rondinella F, de Sanctis N. Prognosis in Legg-Calvé-Perthes' disease: a new classification by MRI. 17th Meeting of the European Pediatric Orthopaedic Society, Madrid, 1998
Authors' reply:

Sir,

It is widely accepted that the prognosis in Perthes' disease reflects the extent of deformation of the femoral head and the loss of acetabular containment. These mechanical alterations are determined by two key biological factors, the size of the epiphyseal infarction and the age of the child. Early prediction of the likely prognosis is therefore central to a rational plan of treatment, and is certainly the only means of improving outcome in those hips which are destined to do badly.

In our paper we were careful to compare all the radiological parameters in current use, including the lateral pillar classification ${ }^{1}$ since this is applicable in the fragmentation stage, before the occurrence of extrusion of the femoral head and loss of containment. The role of MRI has yet to be established in the treatment of Perthes' disease. We find that it defines the extent of the epiphyseal infarct, but has not been shown to demonstrate the shape or subluxation of the femoral head more clearly than multiple-view arthrography. ${ }^{2,3}$ Hochbergs et $\mathrm{al}^{4}$ could not establish a convincing correlation between the Catterall classification and MR changes, noting that in groups III and IV almost the entire epiphysis showed signal changes.

We cannot comment upon Dr Meiss's assertion that MRI defines loss of containment, labrum lift and growth-plate changes, and that his treatment to prevent these changes is effective, since he refers only to abstracts of his presentations. His outcome studies after treatment, published in a peer-reviewed journal, are awaited with interest.

M. F. MACNICOL, MCh, FRCS Ed(Orth)

A. M. ISMAIL, FRCS Ed(Orth)

Princess Margaret Rose Orthopaedic Hospital and the Royal Hospital for Sick Children

Edinburgh, UK.

1. Herring JA, Neustadt JB, Williams JJ, Early JS, Browne RH. The lateral pillar classification of Legg-Calvé Perthes disease. J Pediatr Orthop 1992;12:143-50.

2. Hochbergs P, Eckerwall G, Egund N, Jonsson K, Wingstrand H. Femoral head shape in Legg-Calvé-Perthes' disease: correlation between conventional radiography, MR imaging, bone scintigraphy and arthrography. Acta Radiol 1994;35:545-8.

3. Kaniklides C, Lonnerholm I , Moberg A, Sahlstedt B. Legg-CalvéPerthes' disease: comparison of conventional radiography, MR imaging, bone scintigraphy and arthrography. Acta Radiol 1995;36: 434-9.

4. Hochbergs P, Eckerwall G, Wingstrand H, Egund N, Jonsson K. Epiphyseal bone-marrow abnormalities and restitution in Legg-CalvéPerthes' disease. Acta Radiol 1997;38:855-62.

\section{Different methods of treatment related to the bilateral occurrence of Perthes' disease}

Sir,

I wish to comment on the article in the November 1997 issue by Futami and Suzuki entitled 'Different methods of treatment related to the bilateral occurrence of Perthes' disease'.

The idea is put forward that weight-bearing in an abduction cast, fixing the legs in moderate internal rotation, may be favourable to the natural history because the contralateral side seems to be protected from the manifestations of the disease.

I would like to ask the authors two questions: first, has this treatment been beneficial to the primarily affected side and, secondly, how much did these casts reduce the children's normal activity and how many steps were they able to walk?

My own measurements using a pedometer indicate that an 
active child walks between 10000 and 20000 steps per day. I would suspect that it is not so much the containment principle that works in this group of Japanese children but protection from repetitive stress. The excellent studies of Lauritzen ${ }^{2}$ and Meyer ${ }^{3}$ in recumbency and in the use of a wheelchair support the latter principle. My own experience with a rigid wheelchair regime points in the same direction. ${ }^{4}$

I realise that wheelchair treatment is not a very attractive therapeutic option, but it is probably less cumbersome than having to wear abduction casts.

L. MEISS, MD

Orthopädische Universitätsklinik

Hamburg, Germany.

1. Futami T, Suzuki S. Different methods of treatment related to the bilateral occurrence of Perthes' disease. J Bone Joint Surg [Br] 1997; 79-B:979-82.

2. Lauritzen J. Legg-Calvé-Perthes' disease. Acta Orthop Scand 1975; 159:1-137.

3. Meyer J. Legg-Calvé-Perthes' disease: radiological results of treatment and their late clinical consequences: a study of the efficacy of three methods of treatment: wheelchair, bedrest without traction, traction in bed. Acta Orthop Scand 1977;167:1-131.

4. Meiss L, Schaefer B, Mallien O. Morbus Perthes - aggressives Zuwarten versus schonende Operation. In: Hoffstetter/Jerosch (Hrsg). Kontroverses in der kinderorthopädie Aachen: 1995;Chaled Shaker 121-36.

\section{Author's reply:}

Sir,

Professor Meiss indicated two important points in our article. The Scottish Rite brace has been popular in Japan because it is simple to apply. The results in patients so treated were not satisfactory. In 1992 Tamura, at the Annual Meeting of the Japanese Pediatric Orthopaedic Association, demonstrated excellent results in a series treated consecutively by a modified abduction cast.

It may be cumbersome for young children to wear the abduction cast and it can reduce the normal activity of the patients. Unfortunately, we do not have data on the number of steps per day in the cast. Meyer ${ }^{3}$ reported rates of bilateral occurrence in three series, respectively: in a wheelchair $15.6 \%$; bed rest, $15.1 \%$; and traction in bed, $17.5 \%$. Treatment by non-weight-bearing therefore does not appear to reduce bilateral occurrence. We agree that the repetitive stress to the femoral head is an important factor in bilateral involvement, but we believe that stress may not affect the vulnerable epiphysis if the femoral head is contained.

\section{T. FUTAMI, MD}

Medical Centre for Children

Shiga, Japan.

1. Martinez AG, Weinstein SL, Diez FR. The weight-bearing abduction brace for the treatment of Legg-Perthes disease. J Bone Joint Surg [Am] 1992;74-A:12-21.

2. Meehan PL, Angel D, Nelson JM. The Scottish Rite abduction orthosis for the treatment of Legg-Perthes disease: a radiographic analysis. J Bone Joint Surg [Am] 1992;74-A:2-12.

3. Meyer J. Legg-Calvé-Perthes disease: radiological results of treatment and their late clinical consequences. Acta Orthop Scand 1977;167.

\section{Treatment of displaced proximal humeral fractures in elderly patients}

Sir,

I read with interest the paper in the May 1997 issue by Zyto et al ${ }^{1}$ entitled 'Treatment of displaced proximal humeral fractures in elderly patients'. It had the selection criteria of 'three- or fourpart fractures of the humerus', a phrase that specifically identifies the use of Neer's classification system, and ended with the strong assumption that there was no significant difference in shoulder function with regard to the type of treatment. This statement could prove to be misleading. It is well established that loose application of Neer's classification system such as with two radiographs per patient cannot hope to achieve accurate radiological analysis of proximal humeral fractures. ${ }^{2-4}$ Furthermore, it appeared that the authors did not adjust for unknown confounding factors.

To this end, the blanket statement that "...the outcome of surgical and conservative treatment of three-part fractures of the proximal humerus in elderly patients is similar..." is only true for the modified method used by the authors and may not be true at all if Neer's classification system is strictly applied.

H. A. KARLADANI

Gothenburg University

Sweden.

1. Zyto K, Ahrengart L, Sperber A, Törnkvist H. Treatment of displaced proximal humeral fractures in elderly patients. J Bone Joint Surg [Br] 1997;79-B:412-7.

2. Pavlov H, Warren RF, Weiss CB Jr, Dines DM. The roentgenographic evaluation of anterior shoulder instability. Clin Orthop 1985; 194:153-8.

3. Flatow EL, Ulrich C. Humerus. Oxford: Butterworth-Heinemann, 1995;58.

4. Neer CS II. Displaced proximal humeral fractures Part I: classification and evaluation. J Bone Joint Surg [Am] 1970;52-A:1077-89.

\section{Author's reply:}

Sir,

I thank Dr Karladani for his comments. Before the start of any treatment the fracture pattern should be analysed and a valid classification system can be a useful tool for selecting the optimal treatment. Neer's classification system is commonly used. It is based on four different anatomical fragments of the fractured proximal humerus. ${ }^{1}$ Recently, the reliability and reproducibility of the Neer classification system have been questioned. ${ }^{2-4}$ Sidor et $\mathrm{al}^{5}$ have shown that five different observers agreed on the final classification for only one-third of the fractures, indicating that the Neer classification system is of little value for interpreting comminuted fractures of the proximal humerus. Newer techniques for accurate radiological evaluation, such as CT and three-dimensional analysis, have not improved the accuracy of classification of the fracture pattern. ${ }^{6}$ Unfortunately, we do not have a better one.

For the radiological assessment of the fractured arm, we used the AP and lateral views. We agree that there is perhaps some inaccuracy in how we classified the fracture pattern, but this is strictly theoretical because clinically we had to use the available system with all its limitations. It is doubtful if we would have achieved improved accuracy of analysis of the fracture pattern with more radiological views or more sophisticated techniques.

Our rationale for using limited internal fixation is explained in the text. Surgery improved the position of the fracture which was maintained during the healing process.

We believe that our results do not reflect the classification system but that there are other factors to be considered such as the osteoporotic bone, the degenerative cuff and the low patient compliance.

K. ZYTO, MD, PhD

Söder Hospital

Stockholm, Sweden. 
1. Neer CS II. Displaced proximal humeral fractures. Part II. Treatment of three part and four part displacement. J Bone Joint Surg [Am] 1970; 52-A:1090-103.

2. Kristiansen B, et al. The Neer classification of fractures of the proximal humerus: an assessment of interobserver variation. Skeletal Radiol 1988;17:420-2.

3. Siebenrock AA, Gerber $\mathbf{C}$. The reproducibility of classification of fractures of the proximal end of the humerus. J Bone Joint Surg [Am] 1993;75-A:1751-5.

4. Bernstein J, et al. Evaluation of the Neer system of classification of proximal humeral fractures with computerized tomographic scans and plain radiographs. J Bone Joint Surg [Am] 1996;78-A:1371-5.

5. Sidor ML, Zuckerman JD, Lyon T, et al. The Neer classification system for proximal humeral fractures: an assessment of interobserver reliability and intraobserver reproducibility. J Bone Joint Surg [Am] 1993;75-A:1745-50.

6. Sjöden, et al. 3D-radiographic analysis does not improve the reproducibility of fracture classification in the proximal humerus. Presented at the 10th Congress of the European Society for Surgery of the Shoulder and the Elbow, Salzburg, 1997.

\section{The conservative management of acute pyogenic iliopsoas abscess in children}

Sir,

I read with interest the article entitled 'The conservative management of acute pyogenic iliopsoas abscess in children' by Tong et $\mathrm{al}^{1}$ in the January 1998 issue. We have reported a similar series ${ }^{2}$ and suggested that pyogenic iliopsoas abscess should be termed 'retrofascial pyogenic iliac fossa abscess'. The reasons for this were that an iliopsoas abscess is localised in the iliac fossa and the iliacus and psoas muscles are retrofascial.

A. K. JAIN, MS(Orth)

University College of Medical Sciences

Delhi, India.

1. Tong CWC, Griffith JF, Lam TP, Cheng JCY. The conservative management of acute pyogenic iliopsoas abscess in children. $J$ Bone Joint Surg [Br] 1998;80-B:83-5.

2. Jain AK, Kumar S, Shiv V, Singh H, Tuli SM. Retrofascial pyogenic iliac fossa abscess: 20 cases studied by ultrasonography. Acta Orthop Scand 1992;63:53-6.

\section{Author's reply:}

Sir,

We thank Dr Jain for his comment. Our paper only included children and no adults. Because of the different terminology Dr Jain's article was not included in our literature search.

J. C. Y. CHENG, FRCS Ed(Orth)

Prince of Wales Hospital

Hong Kong. 